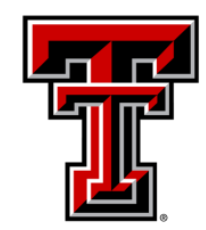

TEXAS TECH UNIVERSITY

Libraries"

\title{
INVESTIGATING THE INFLUENCE OF SHAME, DEPRESSION, AND DISTRESS TOLERANCE ON THE RELATIONSHIP BETWEEN INTERNALIZED HOMOPHOBIA AND BINGE EATING IN LESBIAN AND BISEXUAL WOMEN
}

\section{The Texas Tech community has made this publication openly available. Please share how this access benefits you. Your story matters to us.}

\begin{tabular}{|l|l|}
\hline Citation & $\begin{array}{l}\text { Bayer, V., Robert-Mccomb, J. J., Clopton, J. R., \& Reich, D. A. (2017). } \\
\text { Investigating the influence of shame, depression, and distress } \\
\text { tolerance on the relationship between internalized homophobia } \\
\text { and binge eating in lesbian and bisexual women. Eating Behaviors, } \\
\text { 24, 39-44. https://doi.org/10.1016/i.eatbeh.2016.12.001 }\end{array}$ \\
\hline Citable Link & $\underline{\text { http://hdl.handle.net/2346/73658 }}$ \\
\hline Terms of Use & $\underline{\text { CC BY-NC-ND }}$ \\
\hline
\end{tabular}


Investigating the Influence of Shame, Depression, and Distress Tolerance on the Relationship between Internalized Homophobia and Binge Eating in Lesbian and Bisexual Women

Vanessa Bayer, Jacalyn J. Robert-McComb, James R. Clopton, and Darcy A. Reich Texas Tech University

Author Note

Vanessa Bayer, Department of Psychological Sciences, Texas Tech University; Jacalyn J. Robert-McComb, Department of Kinesiology and Sport Management, Texas Tech University; James R. Clopton, Department of Psychological Sciences, Texas Tech University; Darcy A. Reich, Department of Psychological Sciences, Texas Tech University.

Vanessa Bayer is now at Stuart J. Nathan and Associates in Houston, Texas. Darcy Reich died of cancer on September 12, 2014.

Correspondence concerning this article should be addressed to James R. Clopton, Department of Psychological Sciences, Texas Tech University, Lubbock, Texas 79409-2051. Email: jim.clopton@ttu.edu 


\begin{abstract}
There is limited research evidence about the specific factors influencing disordered eating for lesbian and bisexual women. Therefore, this study investigated relationships among binge eating, internalized homophobia, shame, depression, and distress tolerance in a sample of lesbian $(n=72)$ and bisexual women $(n=66)$. Two hypotheses were tested. First, it was hypothesized that shame and depression would mediate the relationship between internalized homophobia and binge eating. Second, it was hypothesized that distress tolerance would moderate the relationship between shame and binge eating and the relationship between depression and binge eating in the mediation relationships proposed in the first hypothesis. Results indicated that shame was a significant mediator for the relationship between internalized homophobia and binge eating, that depression was not a significant mediator, and that distress tolerance did not moderate the significant mediation relationship between shame and binge eating. The data in this study also indicated that the proportions of lesbian and bisexual participants who reported binge eating and compensatory behavior did not differ significantly, but that bisexual participants reported significantly more depression and shame than lesbian participants.
\end{abstract}


Investigating the Influence of Shame, Depression, and Distress Tolerance on the Relationship between Internalized Homophobia and Binge Eating in Lesbian and Bisexual Women

Eating disorder symptoms are common among lesbian and bisexual women (Feldman \& Meyer, 2007; Heffernan, 1996; Koh \& Ross, 2006; Lakkis, Ricciardelli, \& Williams, 1999; Siever, 1994; Strong, Williamson, Netemeyer, \& Geer, 2000), but previous research has been inconsistent regarding the prevalence of eating disorder symptoms in lesbian and bisexual women. Some studies have found a greater prevalence of eating disorders among lesbian (Heffernan, 1996) or bisexual women (Koh \& Ross, 2006) than among heterosexual women. In contrast, other studies have found equivalent rates of eating disorder symptoms in lesbian, bisexual, and heterosexual women (Feldman \& Meyer, 2007; Strong et al., 2000) or have found higher rates of eating disorder symptoms in heterosexual women (Lakkis et al., 1999; Siever, 1994). Despite that inconsistency, previous research has found that binge eating is the most prominent aspect of disordered eating for lesbian and bisexual women (Austin et al., 2009; Boehmer, Bowen, \& Bauer, 2007; French, Story, Remafedi, Resnick, \& Blum, 1996; Heffernan, 1996; Herzog, Newman, Yeh, \& Warshaw, 1992; Striegel-Moore, Tucker, \& Hsu, 1990). Therefore, the purpose of the present study was to extend previous research by investigating how a few related variables may interact to help explain the likelihood of binge eating among lesbian and bisexual women.

Several related areas of research, including relevant studies of heterosexual women and gay men, led to the hypotheses for the present study. For example, previous research has found that heterosexual women who report more distressing emotions, such as shame and depression, also report more binge eating (e.g., Presnell, Stice, Seidel, \& Madeley, 2009; Sanftner \& Crowther, 1998). One important source of emotional distress for lesbian and bisexual women is 
internalized homophobia--the internalization of negative stereotypes about lesbians, which may lead them to feel negatively about themselves (Heffernan, 1996). A relationship between internalized homophobia and binge eating in lesbian and bisexual women has been repeatedly hypothesized (Beren, Hayden, Wilfley, \& Grilo, 1996; Brown, 1987; Pitman, 1999), and internalized homophobia has been shown to be associated with disordered eating attitudes and behaviors in gay men (Williamson, 1999; Williamson \& Spence, 2001). Furthermore, internalized homophobia has been found to be associated with correlates of disordered eating in lesbian women, including self-objectification and body shame (Haines et al., 2008). Thus, it seems highly likely that internalized homophobia increases the risk of binge eating for lesbian and bisexual women.

Internalized homophobia has been found to be related to shame and depression in lesbian and bisexual women (Allen \& Oleson, 1999; Szymanski, Chung, \& Balsam, 2001). Therefore, because greater levels of shame and depression are associated with a higher frequency of binge eating, higher levels of internalized homophobia may also be associated with higher levels of binge eating. One possible explanation for these associations is that binge eating may be a means for lesbian and bisexual women to regulate negative emotions that result from internalized homophobia. Specifically, internalized homophobia may be associated with binge eating through its relationship with shame and depression. Thus, the following hypothesis was proposed.

Hypothesis 1: For lesbian and bisexual women, the positive relationship between internalized homophobia and binge eating will be mediated by shame and by depression. Specifically, greater levels of internalized homophobia will be associated with greater levels of shame and depression, which will be associated with greater amounts of binge eating. 
Binge eating may be used as a means to escape negative emotions (Anestis, Fink, Smith, Selby, \& Joiner, 2011). In previous research, low distress tolerance was associated with the avoidance of directly and effectively coping with negative emotions, with eating disorder attitudes (Corstorphine, Mountford, Tomlinson, Waller, \& Meyer, 2007), and with emotional eating (Kozak \& Fought, 2011). Anestis, Selby, Fink, \& Joiner (2007) found that lower levels of distress tolerance were associated with higher levels of bulimic behaviors, even when controlling for depressive symptoms and several other covariates (e.g., anxiety symptoms and body dissatisfaction). Lesbian and bisexual women who cannot tolerate the negative emotions associated with internalized homophobia may engage in binge eating. In contrast, those who have higher distress tolerance may be able to cope with the negative emotions associated with internalized homophobia in more adaptive ways. This reasoning led to the following hypothesis.

Hypothesis 2: In the mediation models proposed in Hypothesis 1, the relationship between shame and binge eating and the relationship between depression and binge eating will be moderated by distress tolerance. Specifically, higher levels of shame and depression will be associated with higher levels of binge eating when an individual has a low level of distress tolerance, but not when an individual has a high level of distress tolerance.

\section{Method}

\section{Procedure}

Lesbian and bisexual women were recruited for participation in this study in two ways. Organizations geared towards gay, lesbian, and bisexual individuals (e.g., PFLAG, GSA) distributed information about the study to their members through flyers, e-mail, or posts on their organization's website or Facebook page. Participants were also recruited in general psychology courses at Texas Tech University, but only four participants were recruited this way. The 
students received course credit for research participation, but otherwise participants were not provided with any compensation. In order to have adequate statistical power (.80), data were needed from at least 64 lesbian and 64 bisexual participants (Cohen, 1992).

Approval from the Institutional Review Board at Texas Tech University was obtained prior to data collection. Participants were provided with a web-based link (using Qualtrics Data Collection software) that contained information about the purpose of the study, instructions for the study's questionnaires, and access to the questionnaires. Initially, participants read statements telling them that their participation was voluntary, that their responses would remain anonymous, and that completing the questionnaires would take about 20-30 minutes. After completing the questionnaires, participants were thanked for their participation and asked to forward the link to the study website to anyone else who might qualify for and be interested in participating.

\section{Measures}

Demographic questionnaire. Participants responded to questions about their age, gender, sexual orientation, and ethnicity.

Eating disorder behaviors. A shortened version of the Eating Disorder ExaminationQuestionnaire (EDE-Q; Fairburn \& Beglin, 1994), composed of the six questions asking about the frequency of binge eating and inappropriate compensatory behaviors over the past 28 days, was used in this study. Although the original EDE-Q has separate questions for the purging behaviors it assesses (i.e., vomiting, using laxatives, using diuretics), the current study included a single question that asked about the frequency of any of those behaviors.

Previous research has indicated that the EDE-Q is an internally consistent $(\square=.90$ for the total score) and valid measure of symptoms of eating disorders (Mond, Hay, Rodgers, Owen, \& Beumont, 2004; Peterson et al., 2007). To ensure that participants understood what was meant 
by the statements "an unusually large amount of food" and "a loss of control over eating," they were given standard definitions used in previous research (EDE-Q-I; Goldfein, Devlin, \& Kamenetz, 2005). Objective binge eating was defined as a participant indicating that she eats what other people would consider an unusually large amount of food with a sense of having lost control while eating. Subjective binge eating was defined as having a sense of loss of control over an eating episode that did not involve eating an unusually large amount of food.

Internalized homophobia. A shorter (39 items), bisexual-inclusive version of the Lesbian Internalized Homophobia Scale (LIHS; Szymanski \& Chung, 2001) was used to measure internalized homophobia (Balsam \& Szymanski, 2005; Piggot, 2004, cited in Szymanski, Kashubeck-West, \& Meyer, 2008). Participants rated the extent to which they agreed with statements (e.g., "I feel bad for acting on my lesbian desires.”) on a scale ranging from 1 (strongly disagree) to 7 (strongly agree). Only the Personal Feelings about Being Lesbian/Bisexual subscale was used in this study because it appears to assess the core aspects of homophobia. High scores on this subscale indicate that the individual experiences negative feelings about being lesbian or bisexual (e.g., self-hatred, placing superior value on heterosexuality over homosexuality, and internalized beliefs about being unworthy, sick, or defective because one is lesbian or bisexual). Low scores indicate that the individual feels positive about and is accepting of her lesbian or bisexual identity (e.g., affirming one's identity as lesbian or bisexual, having a strong sense of pride about being lesbian or bisexual; Szymanski \& Chung, 2001).

The shorter version of the LIHS has been found to be internally consistent ( $\alpha=.79$ for the Personal Feelings about Being a Lesbian subscale), to have cross-cultural validity in sexual minority women from 20 different countries, and to correlate positively with measures of 
depression and negatively with measures of self-esteem and psychosexual adjustment (Piggot, 2004, cited in Szymanski et al., 2008).

Shame. The Personal Feelings Questionnaire (PFQ-2; Harder \& Zalma, 1990) is a 22item measure of shame proneness and guilt proneness. In this study, participants responded only to the 10 items of the Shame subscale (e.g., "feeling stupid") and to six filler items with feeling words that do not describe shame or guilt (e.g., "sadness"). Items are rated on a 5-point scale for how often the individual experiences the feeling listed $(0=$ you never experience the feeling; $4=$ you experience the feeling continuously or almost continuously). The Shame subscale has shown adequate internal consistency $(\alpha=.78)$ and excellent 2-week test-retest reliability (.91; Harder $\&$ Zalma, 1990). The PFQ-2 Shame subscale correlates significantly with depression, selfderogation, shyness, and public self-consciousness (Harder, Cutler, \& Rockart, 1992).

Depression. The trait version of the Depression, Anxiety, and Stress Scale (DASS-21) was used to measure depression (Lovibond, 1998). The seven items of the Depression Scale assess the core features of depression (e.g., self-depreciation, loss of interest, dysphoric mood, hopelessness, and anhedonia; Lovibond \& Lovibond, 1995; Lovibond, 1998). For each item (e.g., "I felt that I had nothing to look forward to"), participants indicated how much it described their experience during a typical week in the past 12 months on a 4-point scale $(0=$ Did not apply to me; 3 = Applied to me very much, or most of the time). The DASS-21 has been found to correlate in the expected ways with other measures of depression, anxiety, negative emotions, and positive emotions (Crawford \& Henry, 2003). The Depression scale has excellent internal consistency $(\alpha=.90$; Lovibond \& Lovibond, 1995) and good 8-week test-retest reliability $(r=$ .60; Lovibond, 1997, cited in Lovibond, 1998). 
Distress tolerance. The Distress Tolerance Scale is a 15-item self-report scale measuring perceived ability to tolerate negative emotions (DTS; Simons \& Gaher, 2005). Items are based on four factors hypothesized to be involved in distress tolerance: tolerance of negative emotions, appraisal of negative emotions, regulation of negative emotions, and attention absorbed by negative emotions. Each item (e.g., "Feeling distressed or upset is unbearable to me.") is rated on a 5-point scale ( 1 = strongly agree; 5 = strongly disagree $)$ with high scores indicating high distress tolerance. The DTS has good internal consistency $(\alpha=.82)$. The scale showed convergent and discriminant validity when compared to other measures of emotional functioning (Simons \& Gaher, 2005).

\section{Results}

\section{Characteristics of the Lesbian and Bisexual Participants}

One hundred and seventy-nine individuals participated in this study. Data from 41 potential participants were excluded because of incomplete data or because they were not women who identified their sexual orientation as lesbian or bisexual. The remaining 138 participants identified their sex and gender as female and their sexual orientation as lesbian (72 participants) or bisexual (66 participants). Most participants were Caucasian (73\%). Approximately $7 \%$ of the participants were Latina, 4\% were African-American, $2 \%$ were Asian-American/Pacific Islander, and $10 \%$ were Multiethnic/Biracial. The difference in age for the 32 lesbian $(M=35.0$ years, $S D$ $=13.6$ years $)$ and 38 bisexual $(M=29.3$ years, $S D=9.8$ years $)$ participants who reported their age was not statistically significant, $t(68)=2.10, p>.05$.

All data were analyzed using the Statistical Package for the Social Sciences (SPSS). There were no significant differences in the proportions of lesbian and bisexual women who reported engaging in objective binge eating $\left(19.4 \%\right.$ and $21.2 \%$, respectively), $\chi^{2}(1, N=138)=$ 
$.07, p>.05$, subjective binge eating $(22.2 \%$ and $30.3 \%), \chi^{2}(1, N=138)=1.17, p>.05$, or any type of compensatory behavior $(8.3 \%$ and $12.1 \%), \chi^{2}(1, N=138)=.54, p>.05$. The proportions of lesbian (4.2\%) and bisexual (7.6\%) participants who reported engaging in both objective binge eating and compensatory behavior did not differ significantly, $\chi^{2}(1, N=138)=.73, p>$ .05 , but the higher proportion of bisexual participants (10.6\%) than lesbian participants $(2.8 \%)$ who reported engaging in both subjective binge eating and compensatory behavior approached statistical significance, $\chi^{2}(1, N=138)=3.46, p=.09$.

The mean scores for lesbian and bisexual participants did not differ significantly for distress tolerance, $t(136)=1.39, p>.05$, or for internalized homophobia, $t(136)=.69, p>.05$. However, compared to lesbian participants, bisexual participants reported significantly more shame, $t(136)=-2.10, p<.05$, and depression, $t(136)=-2.17, p<.05($ see Table 1$)$.

Participants in this study reported depressive symptoms that ranged from normal to extremely severe (Lovibond \& Lovibond, 1995), and the mean Depression scores of lesbian $(M=$ $8.58)$ and bisexual $(M=11.94)$ participants were higher than the scores from a nonclinical sample in another study $(M=5.7$; Sinclair et al., 2012). Similarly, lesbian $(M=24.67)$ and bisexual $(M=26.82)$ participants both reported higher levels of shame than those reported in previous research on college students $(M=16.7$; Harder et al., 1992). Participants in the current study had scores that were similar to those reported previously for internalized homophobia (studies of lesbian and bisexual women; Syzmanski, 2005; Szymanski \& Kashubeck-West, 2008) and for distress tolerance (a study of women from the general population; Simons \& Gaher, 2005). 


\section{Data Analyses for Hypothesis 1: Shame and Depression will Mediate the Relationship between Internalized Homophobia and Binge Eating}

Preacher and Hayes' (2008) bootstrapping procedure for mediation analyses was used, specifically the PROCESS macro for SPSS (Hayes, 2012), with rounding to three decimal places (Chang, Jarry, \& Kong, 2014; White \& Turner, 2014). The bootstrapping method calculates the total effect of the independent variable (i.e., internalized homophobia) on the dependent variable (i.e., binge eating) when the mediator (i.e., shame or depression) is not accounted for, the direct effect of the independent variable on the dependent variable when accounting for the variance in the dependent variable attributed to the mediator, and the indirect effect of the independent variable on the dependent variable through the mediator. Significant mediation is found when the confidence interval for the indirect effect does not include zero (Preacher \& Hayes, 2008). Before mediation analyses were performed, the bivariate correlations between the variables in the mediation model were computed, and all variables included in the mediation analyses were correlated with each other significantly $(p<.05)$.

\section{Shame mediating the relationship between internalized homophobia and objective}

binge eating. In the first mediation model, after accounting for the indirect effect of internalized homophobia on objective binge eating through shame, the direct effect of internalized homophobia on objective binge eating was not significant, $b=.256, S E=.183, t(136)=1.40, p>$ .05. The bias-corrected bootstrap estimate of the indirect effect of internalized homophobia (.113) on objective binge eating through shame was significant given that the $95 \%$ confidence interval (.289 to .009) did not contain 0. Thus, shame mediated the effect of internalized homophobia on objective binge eating. 


\section{Shame mediating the relationships between internalized homophobia and subjective}

binge eating. Shame partially mediated the relationship between internalized homophobia and subjective binge eating because the direct effect of internalized homophobia on subjective binge eating was significant, $b=.485, S E=.160, t(136)=3.04, p<.01$, and because of the significant indirect effect of internalized homophobia (.117) on subjective binge eating through shame, given that the $95 \%$ confidence interval for the indirect effect (.297 to .005) did not contain 0 .

\section{Depression as a mediator in the relationships between internalized homophobia and} objective or subjective binge eating. Depression did not mediate the relationship between internalized homophobia and either objective or subjective binge eating. The direct effect of internalized homophobia on objective binge eating was not significant, $b=.270, S E=.184$, $t(136)=1.46, p>.05$. The bias-corrected bootstrap estimates of the indirect effects of internalized homophobia on objective binge eating through depression was not significant given that the $95 \%$ confidence interval for the indirect effect included zero $(95 \%$ confidence interval $=$ .306 to -.030). The direct effect of internalized homophobia on subjective binge eating was significant, $b=.533, S E=.162, t(136)=3.29, p<.01$. The bias-corrected bootstrap estimate of the indirect effect of internalized homophobia on subjective binge eating through depression was not significant given that the $95 \%$ confidence interval (.247 to -.070) contained zero.

Hypothesis 1 proposed that the relationships between internalized homophobia and binge eating would be mediated by depression and shame. This hypothesis was supported for shame, but not for depression. In particular, shame fully mediated the relationship between internalized homophobia and objective binge eating and partially mediated the relationship between internalized homophobia and subjective binge eating. 


\section{Data Analyses for Hypothesis 2: For the Significant Mediation Models Supporting Hypothesis 1, the Relationship between Depression and Binge Eating and the Relationship between Shame and Binge Eating will be Moderated by Distress Tolerance}

It was expected that the relationship between depression and binge eating and the relationship between shame and binge eating would not be as strong for individuals with a greater ability to tolerate distress. Preacher and Hayes' (2008) bootstrapping procedure for moderated mediation analyses was used to determine whether distress tolerance significantly moderated the indirect effects found in the mediation models. Because depression was not a significant mediator for the relationship between internalized homophobia and binge eating (Hypothesis 1), only two models were analyzed to test Hypothesis 2. One model examined whether distress tolerance moderated the shame-objective binge eating relationship in the mediation model for internalized homophobia, and the other examined whether distress tolerance moderated the shame-subjective binge eating relationship in the mediation model for internalized homophobia. Distress tolerance did not significantly moderate the shame-binge eating relationships when included in either of those mediation models because in each case the $95 \%$ confidence interval contained zero (.023 to -.063 for objective binge eating, and .050 to -.042 for subjective binge eating). Thus, the relationship between shame and binge eating was not significantly influenced by the degree to which an individual can tolerate distress, so Hypothesis 2 was not supported by the data in this study.

\section{Discussion}

This study adds to the research literature demonstrating that shame is a central psychological characteristic of eating disorders (Goodheart, Gibson, \& Clopton, 2012). Shame fully mediated the relationship between internalized homophobia and objective binge eating, and 
partially mediated the relationship between internalized homophobia and subjective binge eating. In other words, lesbian and bisexual women who reported negative feelings about their sexual orientation reported higher amounts of objective binge eating because of the higher levels of shame they experienced, and they also reported higher levels of subjective binge eating, in part because of their higher levels of shame.

Women and girls are more vulnerable to engaging in binge eating and developing eating disorders if they regard themselves as being unattractive because of a perceived discrepancy between the way they view their bodies and the way that they would like to look (Fredrickson \& Roberts, 1997; Skarderud, 2007). Body dissatisfaction and feelings of shame about being unattractive also occur for lesbian and bisexual women (Huxley, Clarke, \& Halliwell, 2014). They may experience an additional source of shame contributing to the development of eating disorders if they internalize condemnation and other negative societal attitudes about homosexuality, and as a result see themselves as inherently flawed because of their sexual orientation.

Shame contributes to the development of eating disorders and prevents women with eating disorders from seeking and becoming fully involved in treatment. Once an eating disorder such as bulimia has begun, shame increases following episodes of binge eating, increases the urge to vomit, but persists even after vomiting (Corstophine, Waller, Ohanian, \& Baker, 2006; Hinrichsen, Morrison, Waller, \& Schmidt, 2007). Eating disorders have been described as "disorders of shame" because behaviors related to shame, such as avoidance and secrecy, are so common among women with eating disorders (Gilbert, 1998; Kaufman, 1989). Women with eating disorders seek to conceal their eating disorders and the shame that they feel. Therefore, they are reluctant to seek help for their eating disorders, and if they are in treatment, they may 
not be fully honest about their symptoms and may be tempted to prematurely end treatment (Striegel-Moore \& Marcus, 1995).

The reduction of internalized homophobia and shame is an important goal for therapy when working with lesbian and bisexual women who binge eat. Shame is likely to lead lesbian and bisexual women to feel reluctant to disclose their sexual orientation, leaving them feeling disconnected from friends, family, and others who could offer social support. Therapists could help lesbian and bisexual women identify people to whom they would feel safe disclosing their sexual orientation. Therapists could also help them consider participating in LGB support groups, LGB chat rooms, LGB list-servs, LGB community centers, or LGB-sponsored events (Pachankis, 2007; Weber-Gilmore, Rose, \& Rubenstein, 2011).

Even though the data analyses in this study confirmed the hypothesis about shame, the data analyses did not support expected outcomes for depression and distress tolerance. Depression did not mediate the relationship between internalized homophobia and binge eating, and distress tolerance did not moderate the relationship between shame and binge eating. Distress tolerance may not have moderated the relationship of shame and binge eating because participants with higher levels of distress tolerance were significantly less likely to report shame (-.34) or to report objective (-.17) or subjective binge eating (-.30). Distress tolerance may serve as a protective factor against experiencing shame and engaging in binge eating, or having lower levels of shame and being less likely to engage in binge eating may allow individuals to better tolerate distress. Either of those possibilities indicates that the assumption that distress tolerance would moderate the relationship of shame and binge eating may have been mistaken.

The significant differences in shame and depression for lesbian and bisexual participants may provide a possible explanation regarding why depression did not mediate the relationship 
between internalized homophobia and binge eating. Those significant differences indicate that it would be better in future studies to investigate the experiences of lesbian and bisexual women separately, if sufficiently large samples can be obtained, than to combine them into one group as was done in the current study. The mediation models for depression in this study might have been found to be significant in a larger sample of bisexual women, given that they reported a higher level of depression than lesbian women.

Another limitation to this study was that participants were recruited mostly through LGB organizations, so they may not have been representative of all lesbian and bisexual women. Furthermore, there was no way of knowing how many women viewed the solicitation for participation and no way to estimate the response rate for participation. On the other hand, the participants for this study came from the community and ranged in age from 19 to 69 , so the results may generalize better to the overall population than if the participants had all been college students.

\section{Conclusions}

The present study provides important data about binge eating and compensatory behavior among lesbian and bisexual women. Of most importance, this is one of the first studies to report a significant relationship between internalized homophobia, shame, and binge eating in lesbian and bisexual women. The results of the current study indicate that the shame resulting from internalized homophobia can play a central role in the occurrence of binge eating for lesbian and bisexual women. It is difficult for many lesbian and bisexual women to avoid negative feelings about their sexual orientation in a society where many people believe that homosexuality and bisexuality are unnatural, shameful, and something that can and should be 
changed. Therefore, the effects of these negative feelings need careful attention when mental healthcare professionals are working with lesbian and bisexual clients. 


\section{References}

Allen, D. J., \& Oleson, T. (1999). Shame and internalized homophobia in gay men. Journal of Homosexuality, 37, 33-43. doi: 10.1300/J082v37n03_03

Anestis, M. D., Fink, E. L., Smith, A. R., Selby, E. A., \& Joiner, T. E. (2011). Eating disorders. In M. J. Zvolensky, A. Bernstein, \& A. A. Vujanovic (Eds.), Distress tolerance: Theory, research, and clinical applications. (pp. 245-260). New York: Guilford Press.

Anestis, M. D., Selby, E. A., Fink, E. L., \& Joiner, T. E. (2007). The multifaceted role of distress tolerance in dysregulated eating behaviors. International Journal of Eating Disorders, 40(8), 718-726. doi:10.1002/eat.204

Austin, S. B., Ziyadeh, N. J., Corliss, H. L., Rosario, M., Wypij, D., Haines, J., Camargo, C. A., \& Field, A. E. (2009). Sexual orientation disparities in purging and binge eating from early to late adolescence. Journal of Adolescent Health, 45, 238-245.

doi:10.1016/j.jadohealth.2009.02.001

Balsam, K. F., \& Szymanski, D. M. (2005). Relationship quality and domestic violence in women's same-sex relationships: The role of minority stress. Psychology of Women Quarterly, 29, 258-269. doi: 10.1111/j.1471-6402.2005.00220.x

Beren, S. E., Hayden, H. A., Wilfley, D. E., \& Grilo, C. M. (1996). The influence of sexual orientation on body dissatisfaction in adult men and women. International Journal of Eating Disorders, 20, 135-141. doi: 10.1002/(SICI)1098-108X(199609)20:2<135::AIDEAT3>3.0.CO;2-H 
Boehmer, U., Bowen, D. J., \& Bauer, G. R. (2007). Overweight and obesity in sexual-minority women: Evidence from population-based data. American Journal of Public Health, 97, 1134-1140. doi:10,2105/AJPH.2006.088419

Brown, L. (1987). Lesbians, weight, and eating: New analyses and perspectives. In Boston Lesbian Psychologies Collective (Eds.), Lesbian psychologies: Explorations and challenges (pp. 294-309). Chicago: University of Illinois Press.

Chang, F. M., Jarry, J. L., \& Kong, M. A. (2014). Appearance investment mediates the association between fear of negative evaluation and dietary restraint. Body Image, 11, 7276. doi:10.1016/j.bodyim.2013.11.002

Cohen, J. (1992). A power primer. Psychological Bulletin, 112, 155-159. doi: 10.1037/00332909.112.1.155

Corstorphine, E., Mountford, V., Tomlinson, S., Waller, G., \& Meyer, C. (2007). Distress tolerance in the eating disorders. Eating Behaviors, 8(1), 91-97. doi:10.1016/j.eatbeh.2006.02.003

Corstorphine, E., Waller, G., Ohanian, V., \& Baker, M. (2006). Changes in internal states across the binge-vomit cycle in bulimia nervosa. Journal of Nervous and Mental Disease, 194, 446-449. doi: 10.1097/01.nmd.0000221303.64098.23

Crawford, J. R., \& Henry, J. D. (2003). The Depression Anxiety Stress Scales (DASS): Normative data and latent structure in a large non-clinical sample. British Journal of Clinical Psychology, 42, 111-131. doi: 10.1348/014466503321903544 
Fairburn, C. G., \& Beglin, S. J. (1994). Assessment of eating disorders: Interview or self-report questionnaire? International Journal of Eating Disorders, 16, 363-370. Retrieved from EBSCOhost.

Feldman, M. B., \& Meyer, I. H. (2007). Eating disorders in diverse lesbian, gay, and bisexual populations. International Journal of Eating Disorders, 40, 218-226. doi: 10.1002/eat

Fredrickson, B. L., \& Roberts, T. (1997). Objectification theory: An explanation for women's lived experiences and mental health risks. Psychology of Women Quarterly, 21, 173-206. doi:10.1111/j.1471-6402.1997.tb00108.x

French, S. A., Story, M. A., Remafedi, G., Resnick, M. D., \& Blum, R. W. (1996). Sexual orientation and prevalence of body dissatisfaction and eating disordered behaviors: A population-based study of adolescents. International Journal of Eating Disorders, 19, 119126. doi:10.1002/(SICI)1098-108X(199603)19:2<119::AID-EAT2>3.0.CO;2-Q

Gilbert, P. (1998). What is shame? Some core issues and controversies. In P. Gilbert \& B. Andrews (Eds.), Shame: Interpersonal behavior, psychopathology, and culture (pp. 3-38). New York: Oxford University Press.

Goldfein, J. A., Devlin, M. J., \& Kamenetz, C. (2005). Eating Disorder ExaminationQuestionnaire with and without instruction to assess binge eating in patients with binge eating disorder. International Journal of Eating Disorders, 37, 107-111. doi:

10.1002/eat.20075 
Goodheart, K. L., Gibson, H. L., Clopton, J. R. (2012). The psychology of eating disorders. In K. L. Goodheart, J. R. Clopton, \& J. J. Robert-McComb (Ed.), Eating disorders in women and children: Prevention, stress management, and treatment (2nd ed., pp. 29-45). Boca Raton, FL: CRC Press.

Haines, M. E., Erchull, M. J., Liss, M., Turner, D. L., Nelson, J. A., Ramsey, L. R., \& Hurt, M. M. (2008). Predictors and effects of self-objectification in lesbians. Psychology of Women Quarterly, 32,181-187. doi: 10.1111/j.1471-6402.2008.00422.x

Harder, D. W., Cutler, L., \& Rockart, L. (1992). Assessment of shame and guilt and their relationships to psychopathology. Journal of Personality Assessment, 59, 584-604. doi: 10.1207/s15327752jpa5903_12

Harder, D. H., \& Zalma, A. (1990). Two promising shame and guilt scales: A construct validity comparison. Journal of Personality Assessment, 55, 729-745. doi: 10.1207/s15327752jpa5503\&4_30

Hayes, A. F. (2012). PROCESS: A versatile computational tool for observed variable mediation, moderation, and conditional process modeling. Retrieved from http://www.afhayes.com/public/process2012.pdf.

Heffernan, K. (1996). Eating disorders and weight concern among lesbians. International Journal of Eating Disorders, 19, 127-138. doi: 10.1002/(SICI)1098108X(199603)19:2<127::AID-EAT3>3.0.CO;2-P 
Herzog, D. B., Newman, K. L., Yeh, C. J., \& Warshaw, M. (1992). Body image satisfaction in homosexual and heterosexual women. International Journal of Eating Disorders, 11, 391396. doi: 10.1002/1098-108X(199205)11:4<391::AID-EAT2260110413>3.0.CO;2-F

Hinrichsen, H., Morrison, T., Waller, G., \& Schmidt, U. (2007). Triggers of self-induced vomiting in bulimic disorders: The roles of core beliefs and imagery. Journal of Cognitive Psychotherapy, 21, 261-272. doi:10.1891/088983907781494528

Huxley, C. J., Clarke, V., \& Halliwell, E. (2014). A qualitative exploration of whether lesbian and bisexual women are "protected" from sociocultural pressure to be thin. Journal of Health Psychology, 19, 273-284. doi:10.1177/1359105312468496

Kaufman, G. (1989). The psychology of shame. New York: Springer.

Koh, A. S., \& Ross, L. K. (2006). Mental health issues: A comparison of lesbian, bisexual, and heterosexual women. Journal of Homosexuality, 51, 33-57. doi: 10.1300/J082v51n01_03

Kozak, A. T., \& Fought, A. (2011). Beyond alcohol and drug addiction. Does the negative trait of low distress tolerance have an association with overeating? Appetite, 57(3), 578-581. doi:10.1016/j.appet.2011.07.008

Lakkis, J., Ricciardelli, L. A., \& Williams, R. J. (1999). Role of sexual orientation and genderrelated traits in disordered eating. Sex Roles, 41, 1-16. doi: 10.1023/A:1018829506907

Lovibond, P. F. (1998). Long-term stability of depression, anxiety, and stress syndromes. Journal of Abnormal Psychology, 107, 520-526. doi: 10.1037/0021-843X.107.3.520 
Lovibond, P. F., \& Lovibond, S. H. (1995). The structure of negative emotional states:

Comparison of the Depressions Anxiety Stress Scales (DASS) with the Beck Depression and Anxiety Inventories. Behavior Research and Therapy, 33, 335-343. doi: 10.1016/00057967(94)00075-U

Mond, J. M., Hay, P. J., Rodgers, B., Owen, C., \& Beumont, P. J. (2004). Validity of the Eating Disorder Examination Questionnaire (EDE-Q) in screening for eating disorders in community samples. Behavior Research and Therapy, 42, 551-567. doi:10.1016/S00057967(03)00161-X

Pachankis, J. E. (2007). The psychological implications of concealing a stigma: A cognitiveaffective-behavioral model. Psychological Bulletin, 133, 328-345. doi:10.1037/00332909.133.2.328

Peterson, C. B., Crosby, R. D., ... le Grange, D. (2007). Psychometric properties of the Eating Disorder Examination-Questionnaire: Factor structure and internal consistency. International Journal of Eating Disorders, 40, 386-389. doi: 10.1002/eat.20373

Pitman, G. E. (1999). Body image, compulsory heterosexuality, and internalized homophobia. Journal of Lesbian Studies, 3, 129-139. doi: 10.1300/J155v03n04_17

Preacher, K. J., \& Hayes, A. F. (2008). Asymptotic and resampling strategies for assessing and comparing indirect effects in multiple mediator models. Behavior Research Methods, 40, 879-891. doi: 10.3758/BRM.40.3.879 
Presnell, K., Stice, E., Seidel, A., \& Madeley, M. C. (2009). Depression and eating pathology: Prospective reciprocal relations in adolescents. Clinical Psychology and Psychotherapy, 16, 357-365. doi: 10.1002/cpp.630

Sanftner, J. L., \& Crowther, J. H. (1998).Variability in self-esteem, moods, shame and guilt to eating disorder symptomatology. Journal of Social and Clinical Psychology, 14, 315-324. doi: 10.1002/(SICI)1098-108X(199805)23:4<391::AID-EAT6>3.0.CO;2-D

Siever, M. D. (1994). Sexual orientation and gender as factors in socioculturally acquired vulnerability to body dissatisfaction and eating disorders. Journal of Consulting and Clinical Psychology, 62, 252-260. doi: 10.1037/0022-006X.62.2.252

Simons. J. S., \& Gaher, R. M. (2005). The Distress Tolerance Scale: Development and validation of a self-report measure. Motivation and Emotion, 29, 83-102. doi: 10.1007/s11031-0057955-3

Sinclair, S. J., Siefert, C. J., Slavin-Mulford, J. M., Stein, M. B., Renna, M., \& Blais, M. A. (2012). Psychometric evaluation and normative data for the Depression, Anxiety, and Stress Scales-21 (DASS-21) in a nonclinical sample of U.S. adults. Evaluation and the Health Professions, 35, 259-279. doi: 10.1177/0163278711424282.

Skarderud, F. (2007). Shame and pride in anorexia nervosa: A qualitative descriptive study. European Eating Disorders Review, 2, 81-97. doi:10.1002/erv.774 
Striegel-Moore, R. H., \& Marcus, M. D. (1995). Eating disorders in women: Current issues and debates. In A. L. Stanton \& S. J. Gallant (Eds.), The psychology of women's health: Progress and challenges in research and application (pp. 445-487). Washington, DC: American Psychological Association.

Striegel-Moore, R. H., Tucker, N., \& Hsu, J. (1990). Body image dissatisfaction and disordered eating in lesbian college students. International Journal of Eating Disorders, 9, 493-500. doi: 10.1002/1098-108X(199009)9:5<493::AID-EAT2260090504>3.0.CO;2-C

Strong, S. M., Williamson, D. A., Netemeyer, R. G., \& Geer, J. H. (2000). Eating disorder symptoms and concerns about body differ as a function of gender and sexual orientation. Journal of Social and Clinical Psychology, 19, 240-255. doi: 10.1521/jscp.2000.19.2.240

Szymanski, D. M. (2005). Heterosexism and sexism as correlates of psychological distress in lesbians. Journal of Counseling and Development, 83, 355-360. doi: 10.1002/j.15566678.2005.tb00355.x

Szymanski, D. M., \& Chung, Y. B. (2001). The Lesbian Internalized Homophobia Scale: A rational/theoretical approach. Journal of Homosexuality, 41, 37-52. doi: 10.1300/J082v41n02_03

Szymanski, D. M., Chung, Y. B., \& Balsam, K. F. (2001). Psychosocial correlates of internalized homophobia in lesbians. Measurement and Evaluation in Counseling and Development, 34, 27-38. Retrieved from EBSCOhost. 
Szymanski. D. M., \& Kashubeck-West, S. (2008). Mediators of the relationship between internalized oppressions and lesbian and bisexual women's psychological distress. The Counseling Psychologist, 36, 575-594. doi: 10.1177/0011000007309490.

Szymanski. D. M., Kashubeck-West, S., \& Meyer, J. (2008). Internalized heterosexism: A historical and theoretical overview. The Counseling Psychologist, 36, 510-524. doi: $10.1177 / 0011000007309488$

Weber-Gilmore, G., Rose, S., \& Rubinstein, R. (2011). The impact of internalized homophobia on outness for lesbian, gay, and bisexual individuals. The Professional Counselor: Research and Practice, 1, 163-175. Retrieved from EBSCOhost.

White, B. A., \& Turner, K. (2014). Anger rumination and effortful control: Mediation effects on reactive but not proactive aggression. Personality and Individual Differences, 56, 186-189. doi:10.1016/j.paid.2013.08.012

Williamson, I. (1999). Why are gay men a high risk group for eating disturbance? European Eating Disorders Review, 7, 1-4. doi:10.1002/(SICI)1099-0968(199903)7:1<1::AIDERV275>3.0.CO;2-U

Williamson, I., \& Spence, K. (2001). Towards an understanding of risk factors for eating disturbance amongst gay men. Health Education, 101, 217-227. doi: 10.1108/EUM0000000005645. 
Table 1

Group Means and Standard Deviations for Depression, Shame, Internalized Homophobia, Distress Tolerance, and "Outness"

\begin{tabular}{|c|c|c|c|c|c|}
\hline \multirow[b]{2}{*}{ Variable } & \multicolumn{2}{|c|}{ Lesbian } & \multicolumn{2}{|c|}{ Bisexual } & \multirow[b]{2}{*}{$t(136)$} \\
\hline & $M$ & $S D$ & $M$ & $S D$ & \\
\hline Depression & 8.58 & 9.26 & 11.94 & 9.12 & $-2.17 *$ \\
\hline Shame & 24.67 & 5.62 & 26.82 & 6.44 & $-2.10 *$ \\
\hline Internalized homophobia & 2.00 & .82 & 2.50 & .91 & -.69 \\
\hline Distress tolerance & 3.65 & 1.03 & 3.40 & 1.07 & 1.39 \\
\hline "Outness" & 4.20 & 1.43 & 2.70 & 1.50 & $6.13 * *$ \\
\hline
\end{tabular}

$* p, .05 ; * * p<.001$ 